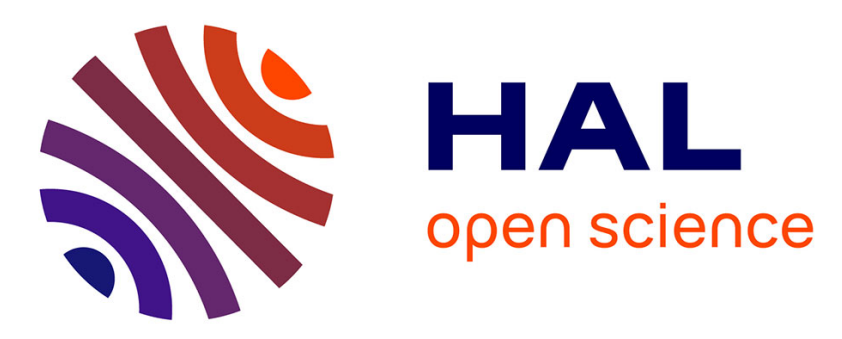

\title{
Synthetic 3D diamond-based electrodes for flexible retinal neuroprostheses: Model, production and in vivo biocompatibility
}

Amel Bendali, Lionel Rousseau, Gaelle Bazin Lissorgues, Emmanuel Scorsone, Milan Djilas, Julie Dégardin, Elisabeth Dubus, Stéphane Fouquet, P.

Bergonzo, Ryad Benosman, et al.

\section{To cite this version:}

Amel Bendali, Lionel Rousseau, Gaelle Bazin Lissorgues, Emmanuel Scorsone, Milan Djilas, et al.. Synthetic 3D diamond-based electrodes for flexible retinal neuroprostheses: Model, production and in vivo biocompatibility. Biomaterials, 2015, 67, pp.73-83. 10.1016/j.biomaterials.2015.07.018 . hal01190753

\section{HAL Id: hal-01190753 \\ https: / hal.sorbonne-universite.fr/hal-01190753}

Submitted on 1 Sep 2015

HAL is a multi-disciplinary open access archive for the deposit and dissemination of scientific research documents, whether they are published or not. The documents may come from teaching and research institutions in France or abroad, or from public or private research centers.
L'archive ouverte pluridisciplinaire HAL, est destinée au dépôt et à la diffusion de documents scientifiques de niveau recherche, publiés ou non, émanant des établissements d'enseignement et de recherche français ou étrangers, des laboratoires publics ou privés. 
1 Synthetic 3D diamond-based electrodes for flexible retinal neuroprostheses: model,

2 production and in vivo biocompatibility

3

4 Amel Bendali ${ }^{1,2,3}$, Lionel Rousseau ${ }^{4}$, Gaëlle Lissorgues ${ }^{4}$, Emmanuel Scorsone ${ }^{5}$, Milan Djilas ${ }^{1,2,3}$, Julie

5 Dégardin $^{1,2,3}$, Elisabeth Dubus ${ }^{1,2,3}$, Stéphane Fouquet ${ }^{1,2,3}$, Ryad Benosman ${ }^{1,2,3}$, Philippe Bergonzo ${ }^{5}$

6 José-Alain Sahel ${ }^{1,2,3,6,7,8}$ and Serge Picaud ${ }^{1,2,3^{*}}$

7

$8 \quad{ }^{1}$ INSERM, U968, Institut de la Vision, Paris, F-75012, France ;

9 25orbonne Universités, UPMC Univ Paris 06, UMR_S968, Institut de la Vision, Paris, F-75012, France;

$10 \quad{ }^{3}$ CNRS UMR7210, Institut de la Vision, Paris, 75012, France ;

$11{ }^{4}$ ESIEE - ESYCOM Université Paris Est, Cité Descartes, BP99, 93162 Noisy Le Grand, France ;

$12{ }^{5}$ CEA-LIST, Diamond Sensors Laboratory, Gif-sur-Yvette, France ;

$13 \quad{ }^{6}$ Fondation Ophtalmologique Adolphe de Rothschild, Paris, France ;

$14 \quad{ }^{7}$ CHNO des Quinze-Vingts, Paris ;

$15{ }^{8}$ Academie des Sciences, Paris

16

17

18 * Corresponding author:

19 Serge Picaud, $\mathrm{PhD}$

20 Institut de la Vision

2117 rue Moreau

2275012 Paris

23 France

24 Tel. +33153462592

$25 \quad$ Fax +33153462502

26 E-mail.serge.picaud@inserm.fr 


\section{Abstract}

3 Two retinal implants have recently received the CE mark and one has obtained FDA approval

4 for the restoration of useful vision in blind patients. Since the spatial resolution of current

5 vision prostheses is not sufficient for most patients to detect faces or perform activities of

6 daily living, more electrodes with less crosstalk are needed to transfer complex images to the

7 retina. In this study, we modelled planar and three-dimensional (3D) implants with a distant

8 ground or a ground grid, to demonstrate greater spatial resolution with 3D structures. Using

9 such flexible 3D implant prototypes, we showed that the degenerated retina could mould itself

10 to the inside of the wells, thereby isolating bipolar neurons for specific, independent

11 stimulation. To investigate the in vivo biocompatibility of diamond as an electrode or an

12 isolating material, we developed a procedure for depositing diamond onto flexible 3D retinal

13 implants. Taking polyimide 3D implants as a reference, we compared the number of neurones

14 integrating the $3 \mathrm{D}$ diamond structures and their ratio to the numbers of all cells, including

15 glial cells. Bipolar neurones were increased whereas there was no increase even a decrease in

16 the total cell number. SEM examinations of implants confirmed the stability of the diamond

17 after its implantation in vivo. This study further demonstrates the potential of 3D designs for increasing the resolution of retinal implants and validates the safety of diamond materials for retinal implants and neuroprostheses in general.

21 Keywords: retinal prostheses, 3D electrode, resolution, diamond, bipolar cell, gliosis 


\section{Introduction}

Visual prostheses aim to provide blind patients with useful visual information for face and object recognition, as well as the reading of text and orientation in unknown environment. Despite the degeneration of bipolar cells and retinal ganglion cells, the electrical stimulation of retinal implants has been shown, in clinical trials, to be safe, to enable most blind patients to identify contrasted objects, to follow a line or the ground, and, in some cases, to read short words [1-4]. The Argus II device ( $2^{\text {nd }}$ Sight) has obtained the CE mark and FDA approval, and the Alpha-IMS (Retinal implant AG) has received the CE mark. Preclinical studies are currently evaluating photovoltaic silicon materials [5] or photosensitive polymers [6,7]. Different clinical trials have also demonstrated the ability of suprachoroidal prostheses to activate the degenerated retina when inserted in the space between the sclera and the choroid $[8,9]$. For patients with retinal ganglion cell degeneration in retinal diseases such as glaucoma or diabetic retinopathy, Brindley and his coworkers have pioneered vision prostheses for a direct activation of the visual cortex [10]. These cortical implants have also allowed patients to recover partial vision, but this visual recovery appears to be transient [11]. Finally, psychophysical experiments have indicated that complex visual tasks, such as text reading, orientation in unknown environment or face recognition, would require at least 600 independent pixels [12-14].

The major challenge in visual rehabilitation with neuroprostheses is therefore to increase electrode density whilst increasing the spatial resolution of each electrode, such that each individual electrode generates a pixel. Current retinal prostheses function in a monopolar mode with a distant returning ground, a configuration, for which the spatial distribution of current were investigated electrophysiologically on the chicken retina [15]. However, different electrode configurations were recently described to increase the electrode resolution. For instance, current diffusion can be limited by local return electrodes as in bipolar stimulations using a circular electrode around the stimulating electrode [16]. A quasimonopolar stimulation was also reported to increase the resolution by using a distant return electrode in a plane above hexapolar return electrodes surrounding each stimulating 
1 containment of the activated sites, it increases the threshold level of activation due to the shunting of

2 currents to local return electrodes [17]. In addition, the quasimonopolar stimulations requires complex

3 current injections at each of the hexapolar electrodes [18]. More recently, ground grid with a high

4 conductivity were found to provide a greater focalization of currents [16]. The ground grid

5 configuration should be preferred for high-density arrays because bipolar and quasimonopolar

6 stimulations would increase the number of connecting wires. 3D implant geometries are also thought

7 to improve electrode resolution in the bipolar or ground grid configurations by locally moving neurons

8 between the stimulating and return electrodes [19-21]. The success of such 3D designs implies that the

9 residual blind retina remains sufficiently plastic to mould itself around the 3D structures. This

10 preservation of the flexibility of the residual blind retina was suggested from studies of pillars

11 penetrating the tissue or cavities to be filled with cells [22]. Neurons were found around pillars and in

12 cavities or wells only if the opening was larger than $20 \mu \mathrm{m}$ across $[19,20]$.

Increases in electrode density require a decrease in electrode size and, thus, an increase in the charge density to be injected to achieve neuronal activity. This constraint has driven the search for new materials with greater developed surfaces, such as black platinum or iridium oxide [23]. Materials with a broader electrochemical potential window are also being tested to ensure that the safe charge injection limit is not exceeded. One such material, diamond, is considered particularly attractive, as it displays the broadest electrochemical window of any semiconductor provided it is doped with nitrogen or trimethyl boron $[24,25]$. Nanocrystalline diamond can even be deposited on 3D structures, making it possible to synthesise materials with high aspect ratios and developed structures [26, 27]. Diamond electrodes have even been shown to activate retinal neurons [28]. Finally, diamond has been shown to display biocompatibility in vitro with embryonic cortical neurons and stem cells [29-32] and even retinal neurons [33]. However, this biocompatibility of diamond in vitro does not necessarily imply that it would be biocompatible in the long term in vivo, as other biocompatible materials have been shown to induce retinal gliosis, or even fibrosis, in vivo [19]. Gliosis is classically characterized by the multiplication of glial cells and their consecutive hypertrophy while fibrosis was defined in the above study as the formation of a fibrous preretinal membrane, both cellular events resulting in the spacing between retinal neurons and the implant likely to hamper neuronal stimulation. 


\section{ACCEPTED MANUSCRIPT}

In this study, we first investigated retinal currents in different 3D electrode configurations for

2 image encoding. Because the results of this modelling study are valid only if neurones integrate the 3D

3 structures, we then produced 3D soft implant to examine the tissue implant interfacing. However, this

4 first study was not intended to validate the 3D modelling by physiological measurements. The

5 fabrication procedure was developed to allow the coating of our 3D implants with diamond, for

6 assessing the in vivo biocompatibility of this material. A specific imaging procedure was also used to

7 preserve the tissue/implant interface, making it possible to assess the biocompatibility of diamond in

8 vivo correctly.

9 


\section{Materials \& Methods}

2

\subsection{Modelling}

We created finite-element models of four variants of a $25 \times 25$ stimulating electrode array within a retinal prosthetic system: (i) a planar array with a common counter electrode in the shape of a grid surrounding the stimulating electrodes, (ii) a 3D electrode array with the stimulation electrodes surrounded by a counter electrode grid, again serving as a counter electrode, (iii) a planar electrode array with a distant counter electrode, and (iv) a 3D electrode array with a distant counter electrode. The3D wells were shaped as inverted pyramids with their points cut off at $30 \mu \mathrm{m}$ height (well depth). The well opening edge was $72 \mu \mathrm{m}$ and the well bottom edge was $36 \mu \mathrm{m}$. The stimulation electrode was set to be the entire bottom surface, i.e. square with $36 \mu \mathrm{m}$ edge. The electrode dimensions and shape for the planar electrode were the same as in the 3D array. The inter-electrode distance was 100 $\mu \mathrm{m}$. The electrical conductivity of the tissue was $0.25 \mathrm{~S} / \mathrm{m}$, as in a previous study [20].

For simulation purposes, an image of Abraham Lincoln was cropped and sampled to obtain a square $25 \times 25$ image, the colour palette of which was then reduced from 256 to three levels: white, grey, and black (Figure 1 A-B). The resulting image was then mapped into a finite-element model, by assigning current densities to the stimulating electrodes proportional to the grey levels in the cropped image: zero for white, $1000 \mathrm{~A} / \mathrm{m}^{2}$ for grey and $2000 \mathrm{~A} / \mathrm{m}^{2}$ for black. If we assume a stimulation pulse width of $1 \mathrm{~ms}$, the estimated charge densities would be $0.1 \mathrm{mC} / \mathrm{cm}^{2}$ for grey and $0.2 \mathrm{mC} / \mathrm{cm}^{2}$ for the black intensity levels. These values are below the reported safety limit for platinum $\left(0.35-0.4 \mathrm{mC} / \mathrm{cm}^{2}\right)$ and well below the limit for iridium-oxide $\left(3-4 \mathrm{mC} / \mathrm{cm}^{2}\right)$, and also below the typical levels reported in previous studies [34].

\subsection{Microfabrication and SEM}

Silicon moulds were prepared using $\mathrm{KOH}$ wet etching to generate a 3D structure. A sacrificial oxide layer was then generated over the silicon mould by the thermal oxidation of the wafer in a furnace at $1100^{\circ} \mathrm{C}$ in the presence of oxygen and hydrogen, until a $1 \mu \mathrm{m}$ layer of silicon dioxide was 
1 achieved. Pt electrodes were produced by patterning sputtered Pt over the silicon moulds by standard

2 photolithography. The substrate was then spin-coated with polyimide (PI 2611) to obtain a $10 \mu \mathrm{m}$ -

3 thick layer of polymer. The polyimide was then cured at $450^{\circ} \mathrm{C}$ under nitrogen flow for 6 hours, and a

$4500 \mathrm{~nm}$-thick aluminium film was sputtered over it. We then spin-coated AZ4562 (Clariant, Muttenz,

5 Switzerland) thick photoresist onto the wafer to define the shape of the implant. After the development

6 step, the wafer was placed in $\mathrm{Cl}_{2}$ plasma for reactive ion etching (RIE) of the aluminium layer. The

7 unmasked polymer was etched away with $\mathrm{O}_{2}$ RIE to achieve the final shape of the implant. The

8 aluminium masking was then removed by wet etching. The wafer was immersed in hydrofluoric acid

9 (HF) to etch the sacrificial oxide layer and release the individual implants. Finally the implants were

10 rinsed in DI water and dried.

11 The diamond-based implants were produced as follows. Diamond was selectively grown in 12 silicon moulds as described by Bongrain and coworkers [35]. A microwave plasma enhanced chemical 13 vapour deposition (MPECVD) reactor (Seki AX6500) was used to synthesize diamond in a mixture of 14 methane $\left(\mathrm{CH}_{4}\right)$ and hydrogen $\left(\mathrm{H}_{2}\right)$ gases at a microwave power of $3 \mathrm{~kW}$, a gas pressure 25 mbar, and a substrate temperature of about $800^{\circ} \mathrm{C}$. The diamond layer obtained was about $300 \mathrm{~nm}$ thick. As for the platinum electrodes, the substrate was then covered with a polyimide film and the process used to define the histological implants was identical to that used for Pt-based implants. Polyimide 3D implants were generated with the same procedure without any previous diamond growth.

The implants were imaged with a ZEISS Supra-40 field emission scanning electron microscope (SEM) operating at an acceleration voltage of $2 \mathrm{kV}$. The implants were imaged by SEM after the implantation period. The retinas, fixed together with the implants in paraformaldehyde (see below), were peeled off the implant and the implant was dehydrated in a series of alcohol concentrations (50\%, $70 \%, 90 \%$ and $100 \%$ ethanol).

\subsection{In vivo studies}

Homozygous P23H rats (line 1, kindly provided by Dr Lavail) were housed with a $12 \mathrm{~h}$ dark/12 
1 with European Community Council Directives (86/609/EEC) and with the ARVO (Association for

2 Research in Vision and Ophthalmology) statement for the use of animals in ophthalmic and visual

3 research. Animals were sacrificed by $\mathrm{CO}_{2}$ sedation and cervical dislocation, and all efforts were made

4 to minimize suffering. The surgical procedure used to implant the prototypes has been described in

5 detail elsewhere [36]. Briefly, P23H blind rats were anesthetized by the intraperitoneal injection of a

6 4:1 mixture of ketamine-xylazine (ketamine $100 \mathrm{mg} \mathrm{kg}^{-1}$, xylazine $10 \mathrm{mg} \mathrm{kg}^{-1}$; Ketamine 500; Virbac,

7 Carros, France; xylazine 2\%: Rompun®, Bayer Pharma, Puteaux, France). A small radial sclerotomy

8 (1.5 mm long) was performed behind the limbus with a slit knife. Viscoat ${ }^{\circledR}$ Intraocular Viscoelastic

9 Injection (Alcon Laboratories, Hünenberg, Switzerland) was injected into the subretinal space through the sclerotomy, with a $27 \mathrm{G}$ cannula, to obtain localised retinal detachment. The implant was then inserted into the subretinal space. Immediately after surgery, the correct positioning of the implant was checked in vivo by indirect ophthalmoscopy (frost and lens). In vivo imaging was performed one week after surgery and then again six weeks later, right before the sacrifice, for observation of the eye fundus by endoscopy. A Micron III digital endoscope (Phoenix Research Laboratories, Pleasanton, California) was used for imaging of the eye fundus, together with StreamPix V software and a rat probe.

\subsection{Immunostaining, confocal imaging and quantification}

After six weeks, animals were sacrificed by $\mathrm{CO}_{2}$ sedation and cervical elongation. The eyes were removed and placed in phosphate-buffered saline (PBS, $0.1 \mathrm{M}, \mathrm{pH}$ 7.4). They were dissected so as to retain only the tissue fragment containing the implant. This fragment was fixed by incubation overnight at $4{ }^{\circ} \mathrm{C}$ in paraformaldehyde in PBS (4\% wt/vol) and then rinsed in PBS.

For immunolabelling, retinal fragments were incubated in a blocking solution (10\% bovine serum albumin (Sigma, St. Louis, Missouri), 1\% Triton X-100 (Sigma), $0.5 \%$ Tween 20 (Sigma) and 0.1g/l Thimerosal (Sigma) in PBS) for $1 \mathrm{~h}$ at room temperature. They were then incubated for two days at room temperature with primary antibodies in blocking solution (dilution 1:2). The antibodies used were a polyclonal antibody directed against rabbit PKC $\alpha$ (C-20) (1:1000, Santa Cruz 
1 Biotechnology, Dallas, Texas) and a monoclonal antibody directed against mouse Go $\alpha$ (1:200,

2 Chemicon, Darmstadt, Germany). The fragments were rinsed and then incubated with secondary

3 antibodies: goat anti-mouse $\mathrm{IgG}$ and goat anti-rabbit $\mathrm{IgG}$ antibodies conjugated to Alexa ${ }^{\mathrm{TM}} 594$ and

4 Alexa $^{\mathrm{TM}} 488$, respectively (1:500, Molecular Probes, Invitrogen, Eugene, Oregon) for one day. Cell nuclei were stained with 4',6-diamidino-2-phenylindole (DAPI), which was added during the final incubation period. The implant/retina ensemble was then rinsed and mounted, in permanent mounting medium (MMFrance), on a microscope slide, for viewing under an upright confocal microscope.

Confocal microscopy was performed on an Olympus FV1000 laser-scanning confocal microscope. DAPI counterstaining, AlexaFluor-488 and AlexaFluor-594 and AlexaFluor-647 were detected by excitation with a $405 \mathrm{~nm}$ laser diode, a $488 \mathrm{~nm}$ argon ion laser, and $559 \mathrm{~nm}$ and $635 \mathrm{~nm}$ laser diode lines, respectively. The selection of excitation and emission wavelengths was controlled by appropriate filters: a dichroic mirror (405/488/559/635), SDM490, SDM560, and SDM640 emission beamsplitters and BA430-470, BA505-540, BA575-675 and BA655-755 barrier filters. The primary objective used was an Olympus oil immersion UPLSAPO 20X NA 0.85 -WD 0.20 or UPLFLN 40X NA1.30-WD 0.20 objective. The microscope and image acquisition were controlled with Olympus Fluoview software version 4.1. Images were acquired at a resolution of $1024 \times 1024$ pixels, with a scan rate of $10 \mu$ s.pixel ${ }^{-1}$, with no zoom $(20 \mathrm{x}$ related pixel size: $0.621 \mu \mathrm{m}, 40 \mathrm{x}$ related pixel size: 0.310 $\mu \mathrm{m})$. Images were acquired sequentially, line-by-line, to minimise the crosstalk between excitation and emission, with a step size defined according to the Nyquist-Shannon sampling theorem. Exposure settings minimising the number of oversaturated pixels in the final images were used. Twelve-bit images were then processed with ImageJ or FIJI and converted into 24-bit RGB colour mode. The images were then edited with Adobe Photoshop CS5 software and assembled withAdobe Illustrator CS. The presence of bipolar cells within the wells of 3D-structured implants was assessed by determining the ratio of bipolar cells to the total number of cell nuclei per well for each material: each Z-section was preprocessed to retain only the staining located in each well, and the numbers of bipolar cells and of total cells (DAPI-positive counterstaining) were determined. Bipolar cells were counted with the ImageJ cell counter plug-in and total nuclei were counted semi-automatically with Imaris software (Bitplane AG, Zurich, Switzerland). 


\section{2}

\subsection{Statistical analysis}

We present results for three polyimide implants, five diamond implants and three platinum implants, based on the values of four to nine wells per implant for quantification. All data are expressed as means \pm SEM. The Gaussian distribution of the raw data was tested with a Shapiro-Wilk normality test. One-way ANOVA was then carried out, followed in cases of significance by either a Bonferroni post-hoc test (Gaussian distribution) or Dunns post-hoc test (non-Gaussian distribution), to compare means between groups. Differences were considered significant if $* p<0.05,{ }^{* *} p<0.01$ and $* * * p<0.001$.

\section{Results}

\subsection{Models of implant designs}

Ground grids and 3D electrode designs have been reported to improve the electrical stimulation of retinal tissues [16, 19-21]. Single-electrode models were thus generated to demonstrate the advantage of either a ground grid on a planar substrate [16] or of a 3D well with a ground grid [20]. However, these models were not used to examine the distribution of current in a 3D structure with a distant ground. They were also not used to investigate the distribution of current on an electrode array for image representation. Instead, we examined how a face would be encoded on such electrode arrays. The face of Abraham Lincoln was encoded with a palette of three grey-scale levels (Fig. 1 AB), converted into three current intensities. Finite-element modelling was used to simulate the current density distribution in the retinal tissue above the electrode arrays. Figure 1 illustrates the current densities $40 \mu \mathrm{m}$ above the cathode for the four configurations considered: i) planar electrode array with a returning ground grid (Fig. 1 C), ii) 3D electrode array with a returning ground grid (D), iii) planar electrode array with a distant ground $(\mathbf{E})$, iv) 3D electrode array with a distant ground $(\mathbf{F})$. When calculated on a line running $20 \mu \mathrm{m}$ above the stimulating cathodes (Fig. 2A-D), the current 
1 densities presented square curves above active electrodes within the 3D structures, with or without a

2 ground grid, whereas they yielded peaks above active electrodes on the flat arrays. The introduction of

3 a ground grid (Fig. 2C, D) suppressed the relatively high current measured above inactive electrodes

4 in conditions with a distant ground (Fig. 2A, B), with this baseline current level increasing towards the ground. Quantification of the current densities at a $20 \mu \mathrm{m}$ distance from all electrodes confirmed this

6 large baseline current in configurations with a distant ground (Fig. 2I). As a consequence,, the

7 differences of current densities between positions above active and inactive electrodes are greater in

8 arrays with a ground grid than those generated by the corresponding array with a distant ground. The

9 greatest differences are produced by the 3D array with a ground grid. However, the 3D array with a

10 distant ground is in a similar range or even better than the flat array with a ground grid. The worst

11 case is the flat array with a distant ground, this configuration showing high variability in elicited

12 current densities above inactive and stimulated electrodes limiting thereby the distinction between

13 white and grey levels (Fig.I). At a greater distance from the array (40 $\mu \mathrm{m}$ above the electrodes), the

14 results showed a great reductions of current densities except for the flat array with a distant ground.

15 For the intermediate grey-level stimulations, 3D arrays still show clear peaks of current densities

16 above electrodes (Fig. 2F,H), which are less distinguishable with planar arrays (Fig. 2E, G). However,

17 the quantification of current densities indicated similar differences between gray levels except for the

18 planar array with a ground grid. Again, the planar array with a distant ground exhibits a greater

19 variability in each group limiting thereby the distinctions between grey levels (Fig. 2J). The effect of

20 placing the distant counter electrode eccentrically above the lower right corner of the Lincoln image

21 (rather than above its centre) can be seen on the plots with distant ground configurations (Fig. 2 A-B,

22 E-F). In such instances, the baseline current density increases with decreasing distance from the

23 counter electrode, as all the return charge from all pixels converges on the ground. No such effect is

24 seen for configurations with a grid ground electrode, for which all plots have a constant baseline (Fig.

252 C-D, G-H). These above advantages of 3D implants in neuronal stimulations justify the need to

26 assess innovative materials on such 3D structures. However, these advantages are expected provided

27 neurones to be stimulated integrate into 3D structures. Therefore, to assess the biocompatibility of 
1 diamond and assess neuronal integration in the 3D implants, we developed a fabrication process to 2 generate diamond electrodes on a 3D flexible implant.

\subsection{Production of a diamond-coated 3D flexible foil}

The ability to produce flexible substrates conforming to the curvature of retinal tissues appears to be essential for the maintenance of a correct tissue interface. However, the classical synthesis techniques used to grow diamond are based on high temperatures and microwave plasma techniques that cannot be applied to biocompatible soft substrates. We therefore developed a new solution based on a peel-off process, in which the soft polyimide polymer was deposited on top of a 3D patterned diamond layer. We first generated the 3D structures by preparing silicon moulds by $\mathrm{KOH}$ wet etching, to generate truncated pyramids. These pyramids were obtained by adding a structure to compensate for the etching speed of the 110 and 100 oriented crystalline planes. The process was stopped when the pyramids on the silicon moulds had typically attained a height of $30 \mu \mathrm{m}$ (Figure 3). Diamond was then grown on these 3D silicon moulds, as follows: 1) seeding of the silicon mould with nano-diamond particles (approximately $5 \mathrm{~nm}$ in diameter), 2) sputtering and patterning of an aluminium mask on the silicon mould by photolithography, 3) etching away of the unprotected nano-diamond particles by reactive ion etching (RIE) under oxygen plasma, 4) removal of the aluminium by wet etching, 5) growth of a diamond layer (approximately $300 \mu \mathrm{m}$ thick) around the nano-diamond particles in a microwave plasma enhanced chemical vapour deposition (MPECVD) reactor. The diamond layer was spin-coated with a $10 \mu$ m-thick layer of polyimide (PI 2611), which was then cured. Classical polymer etching was used to define the shape of the implant. Finally, removal of the sacrificial oxide layer led to the release of individual diamond-coated 3D implants.

\subsection{Biocompatibility}

For investigation of the biocompatibility of diamond in vivo, soft polyimide implants with or without diamond or platinum coatings were inserted into the subretinal space of $\mathrm{P} 23 \mathrm{H}$ rats, an animal 
model of retinitis pigmentosa at an age at which the photoreceptors have degenerated. The correct insertion of the implants was checked in vivo using a Micron III numerical endoscope. Images of the eye fundus are provided for the various implants in Figure 4: purely polyimide, metallic, and diamondcoated. The presence of retinal blood vessels above the devices confirmed their subretinal positions. This examination also made it possible to visualise the disappearance of the subretinal bleb generated for introduction of the subretinal implant.

In our investigations of diamond biocompatibility, we had to examine the retinal tissue in the vicinity of the implant. Classically, such examinations are carried out on semi-thin sections or cryostat sections, on which cells can be identified by immunostaining [19-21, 36]. This approach is entirely feasible with soft material dummies (e.g. polyimide) [37], but it is very difficult to cut prototypes containing other hard materials, such as diamond. Implant removal is not a viable option, because the 3D structure enhancing the tissue/interface would complicate the operation. Instead, we developed an innovative approach based on direct confocal imaging of the implant/tissue eye cup whole mounts. We assessed biocompatibility in vivo by visualising cell nuclei and $\mathrm{ON}$ bipolar cell neurons in the 3D wells on whole-mount preparations. The immunostaining protocol was adapted to preserve the implant/tissue interaction while allowing the antibody to diffuse over a distance of $100 \mu \mathrm{m}$ within the retinal tissue (see methods). Figure 5 illustrates such confocal images of the tissue/implant interface for a diamond implant, along views corresponding to different $z$ stacks (view "a": top of the cavities, view "b": bottom of the cavities), shown both with top views (A-F) and orthogonal views (G-H). Cell nuclei were labelled with DAPI (blue) and ON bipolar neurons were immunolabelled with Goa antibodies (green). The $\mathrm{x} 40$ magnification of the retina/implant whole mount makes it possible to visualise the DAPI-stained nuclei in all four cavities. Both the orthogonal views ( $x-z$ axes) and the vertical retinal sections show that retinal bipolar neurons fill the entire cavity, right down to the bottom $(\mathbf{H})$. These data demonstrate that the residual retina is plastic enough to mould itself into the 3D implant wells.

We assessed the biocompatibility of the materials by quantifying cell occupancy in the cavities (Figure 6). This quantification was obtained by generating the 3D reconstruction of the content for each individual well of an implant as illustrated in Figure 6 (A-C). Our strategy for assessing the 
1 material biocompatibility has been to quantify immunolabelled ON bipolar cells to demonstrate the

2 survival of these neurons targeted by subretinal electrical stimulations. However, to define if the

3 material triggered reactive gliosis, we first calculated the total number of cell nuclei because glial cell

4 proliferation would be expected to increase their number and thus to decrease the ratio between

5 neuronal numbers to all cell numbers. The quantification of all cell nuclei was achieved by defining

6 the fluorescent spheres corresponding to DAPI nuclear staining. This quantification indicated that the

7 density of cell nuclei in the implant cavities was greater for polyimide implants $\left(1.5010^{-3} \pm 0.02310^{-3}\right.$

8 cells $\left./ \mu \mathrm{m}^{3}\right)$ than for diamond- $\left(1.1010^{-3} \pm 0.07910^{-3}\right.$ cells $\left./ \mu \mathrm{m}^{3}\right)$ or platinum-coated $\left(1.2110^{-3} \pm 0.189\right.$

$910^{-3}$ cells $/ \mu \mathrm{m}^{3}$ ) implants. These cells can either be neurones of the inner retina (Bipolar cells,

10 horizontal cells, amacrines cells) or glial cells (Müller macroglial cells, microglial cells). Because

11 subretinal implants are intended to depolarize ON bipolar cells, we quantified these neurones in the 3D

12 wells following their immunolabelling. The quantification demonstrated a stability of the ON bipolar

13 cell densities for the different implants except for a platinum-coated implant (Fig. 6F,G). Finally, to

14 get an estimation of retinal gliosis, we calculated the ratio of bipolar cells to all cell nuclei. This ratio

15 was greater with diamond-coated implants $(39.4 \pm 2.3 \%)$ than with the polyimide $(28.9 \pm 1.2 \%)$ or

16 platinum-coated implants $(26.7 \pm 3.5 \%$ ) (Figure $6 \mathrm{H}, \mathrm{I})$. A lack of biocompatibility is expected to

17 induce neuronal degeneration and an associated reactive gliosis with a proliferation of glial cells,

18 which would thus result in a decrease in the neurone to glial cell ratio. Therefore, the higher ratio of

19 bipolar cells to all cells in the diamond wells is consistent with a greater biocompatibility of diamond

20 than polyimide alone or platinum. The absence of a massive inflammatory reaction and the presence of

21 many bipolar neurons in the wells suggest that the various materials used, including diamond in

22 particular, are not toxic to retinal neurons.

\subsection{Characterization of diamond implants}

The original process used here made it possible to produce soft implants with several 3D wells, which were either left uncoated or were coated with either diamond or platinum. The diamond coating covered the entire area of the implant visible on the photograph in Figure $7 \mathbf{B}$ and $\mathbf{E}$, including the 
1 walls and the bottom of the cavities, whereas in the case of platinum the metal coverage appears in

2 light grey colour in panels $\mathbf{C}$ and $\mathbf{F}$. Following in vivo implantation, the surfaces of the implants were 3 observed by scanning electron microscopy (SEM), to assess the physical stability of the implants

4 (results for all three materials tested are shown in Figure 7). On the polyimide implant (A, D), the 5 surface of the material appears similar to that of the freshly produced implants, with no visible defect.

6 Note that the white traces visible on Figure $7 \mathbf{A}$ are due to charge accumulation on this insulating

7 surface during SEM imaging. Similarly, the diamond films $(\mathbf{B}, \mathbf{E})$ showed no discontinuities and the

8 surface was correctly covered. Nevertheless, the very fine cracks observed at the edges of the diamond

9 wells (already present before implantation) indicate that the deposition and growth of the material 10 could be optimised further. Unlike conventional polycrystalline diamond, the diamond surfaces 11 appeared very smooth. This smoothness was a consequence of the process used, with the exposed side 12 of the diamond originally in contact with the silicon surface. Finally, on the metallic implants (C, F), 13 the light grey areas corresponding to the platinum coating also appeared to be free of significant 14 defects and darker due to the presence of organic matter (residual cells). Thus, neither the diamond nor 15 platinum surfaces were damaged by implantation despite the long process from surgery to the cleaning for SEM examination including the immunolabelling and flat mount observation. For all these implants, some cells or tissue remained visible on the implants, particularly within the cavities, as observed on the enlarged views (D-F). This observation confirmed the deep integration of the tissue into the 3D implants, regardless of the material used.

\section{Discussion and Conclusions}

Previous psychophysical studies have demonstrated that retinal implants can allow face recognition, independent locomotion and text reading if they generate at least 600 independent pixels [12-14]. This requires independent stimulation by the individual electrodes of an implant. Current retinal implants are based on classical monopolar stimulation between a stimulating electrode and a distant ground, but other configurations have been proposed, to increase the resolution of individual 
1 concentric electrodes, the quasimonopolar or the introduction of a local returning ground grid [16,

2 17]. Ground grids have already been introduced into some of the planar subretinal implants currently 3 undergoing preclinical testing [5]. In this study, we confirmed that local ground grids were able to 4 decrease current densities in areas surrounding stimulated zones. As previously described [16], we confirmed that a ground grid on a planar array can decrease the current densities above non-stimulated areas. However, we show further that the ground grid on a planar array also decreases the current densities just above stimulated areas requiring therefore higher injected currents to reach an activation threshold. This conclusion is not valid for 3D arrays with a ground grid at short distances $(20 \mu \mathrm{m})$ but becomes tru at greater distance. The use of 3D electrode designs has also been proposed as a means of increasing the resolution of electrical stimulation by restricting the electrical field within cavities between bipolar electrodes [20-22]. We confirmed that 3D configurations increased the local resolution of stimulations with very high current densities within the 3D well. Surprisingly, we also found that, even with a distant ground, 3D configurations also generated very high current densities within the well whilst yielding lower current densities in unstimulated areas than for the planar configuration.

However, the use of a 3D structure is advantageous only if the neuronal tissue remains sufficiently plastic to mould itself onto the $3 \mathrm{D}$ structure, to place neurons between the electrodes. Palanker and his group have shown that the cavities in 3D structures can fill with cell bodies and neurons, depending on the size of the cavity opening [19]. The production of 3D implants should make it possible to position neurons between two electrodes of opposing polarities [21]. The retina has even been shown to mould around pillars [19]. However, given that it may be necessary to remove retinal implants, we preferred well shapes over pillar structures [20]. As previously described in RCS rats [19, 21], we confirmed in $\mathrm{P} 23 \mathrm{H}$ rats, another rodent model of retinitis pigmentosa [38], that the degenerated retina can mould around 3D structures. In a preliminary study, we reported such integration for some retinal sections, but tissue sectioning disrupted the tissue/implant interface [20]. It was therefore not possible to characterize the tissue within the well correctly and, therefore to quantify the bipolar cell neurons present in this volume. In this study, we showed, by imaging retinal whole mounts, that the tissue was in intimate contact with the structures tested: polyimide, platinum, 
1 diamond. We reconstituted the contents of the well and quantified the bipolar neurons present in this

2 small volume. The presence of many bipolar cells in such a well demonstrates the feasibility of

3 activating a retinal column independently of the neighbouring retinal columns in other wells. Our 3D

4 design for subretinal implants would therefore allow the production of independent pixels for each

5 electrode. Electrode impedance were recently reported for chronic implantation [39]. Further studies

6 are required to determine whether similar chronic implantations of 3D designs really do increase the

7 resolution of individual stimulations. Such 3D implant arrays of electrodes could be activated by an

8 ASIC either tethered by wires as in the Argus II implant [40] or connected on the backside of the

9 implant as in the subretinal electronic implant alpha-IMS [1]. However, the production of 10 photosensitive electrode arrays could also solve the difficult issue of tethering the 3D implant to an

11 ASIC [5]. The use of flexible photosensitive polymers would be an additional advantage to enhance 12 the implant/tissue interface $[6,7]$.

Close proximity between tissue and electrode is required for prosthetic applications, as this decreases the diffusion of stimulating currents and increases their geometric localisation. Such tight interactions are required particularly for the development of neuroprostheses, accounting for current interest in the development of novel biocompatible materials with good electronic properties. In addition, two types of current can be generated by electrodes for the electrical stimulation of a neuronal structure: 1) faradic currents, involving chemical oxidation/reduction reactions; 2) capacitive currents, resulting purely from charge accumulation. In neuronal prostheses, capacitive stimulation is favoured, as it limits $\mathrm{pH}$ variation at the surface of the electrode [23]. In the context of visual implants, the need to use small electrodes with a high resolution introduces a supplementary risk of tissue and electrode degradation, resulting from the injection of larger charge densities. It is therefore essential to use materials with high charge injection limits, such as diamond. There has been considerable interest in the use of this carbon-based material for such applications in recent years. Once doped with boron, diamond has excellent electronic and electrochemical properties and is chemically and mechanically inertia [41]. The potential of such diamond electrodes for the stimulation of retinal neurons has been 


\section{ACCEPTED MANUSCRIPT}

1 demonstrated with embryonic cortical neurons and stem cells [29-32] and even retinal neurons [33].

2 Our results further demonstrate the in vivo biocompatibility of diamond on flexible implants.

3

This study confirms that 3D-structured electrodes are advantageous in the design of retinal

4 implants, as they greatly increase the resolution of stimulation. Our findings also highlight the

5 considerable benefits of diamond as an attractive electrode material for neuroprostheses. 


\section{Acknowledgements}

We thank Dr Matthew Lavail for providing the rat $\mathrm{P} 23 \mathrm{H}$ line. $\mathrm{AB}$ received a doctoral

3 fellowship from UPMC. This work was supported by INSERM, UPMC (Paris VI), Foundation

4 Fighting Blindness, the Fédération des Aveugles de France, Fondation de la Recherche Médicale

5 (grant number DBC20101021013) to SP, IRRP, the city of Paris, the Regional Council of Ile-de-

6 France, the French Agence Nationale de la Recherche (ANR) with the MEDINAS project

7 (ANR07TECSAN014), the IMPLANTS project from ITMO-AVIESAN, the European Community's

8 Seventh Framework Programme (FP7/2007-2013) under grant agreement no. 280433 (Neurocare

9 project), and the LabEx LIFESENSES (ANR-10-LABX-65), which was supported by French state

10 funds managed by the ANR within the Investissements d'Avenir programme (ANR-11-IDEX-0004$1102)$ 
3 [1] Zrenner E, Bartz-Schmidt KU, Benav H, Besch D, Bruckmann A, Gabel VP, et al. 4 Subretinal electronic chips allow blind patients to read letters and combine them to words. 5 Proceedings. 2011;278:1489-97.

6 [2] Humayun MS, Dorn JD, Ahuja AK, Caspi A, Filley E, Dagnelie G, et al. Preliminary 6 7 month results from the argus II epiretinal prosthesis feasibility study. Conf Proc IEEE Eng 8 Med Biol Soc. 2009;1:4566-8.

9 [3] Humayun MS, Dorn JD, da Cruz L, Dagnelie G, Sahel JA, Stanga PE, et al. Interim results 10 from the international trial of Second Sight's visual prosthesis. Ophthalmology. $11 \quad 2012 ; 119: 779-88$. Implantation and explantation of an active epiretinal visual prosthesis: 2-year follow-up data from the EPIRET3 prospective clinical trial. Eye (Lond). 2012;26:501-9.

[5] Mathieson K, Loudin J, Goetz G, Huie P, Wang L, Kamins T, et al. Photovoltaic retinal prosthesis with high pixel density. . Nature Photonics 2012;6:391-7.

[6] Lee SW, Seo JM, Ha S, Kim ET, Chung H, Kim SJ. Development of microelectrode arrays for artificial retinal implants using liquid crystal polymers. Investigative ophthalmology \& visual science. 2009;50:5859-66.

[7] Ghezzi D, Antognazza MR, Dal Maschio M, Lanzarini E, Benfenati F, Lanzani G. A hybrid bioorganic interface for neuronal photoactivation. Nat Commun. 2011;2:166.

[8] Nayagam DA, Williams RA, Allen PJ, Shivdasani MN, Luu CD, Salinas-LaRosa CM, et al. Chronic electrical stimulation with a suprachoroidal retinal prosthesis: a preclinical safety and efficacy study. PloS one. 2015;9:e97182.

[9] Fujikado T, Kamei M, Sakaguchi H, Kanda H, Morimoto T, Ikuno Y, et al. Testing of semichronically implanted retinal prosthesis by suprachoroidal-transretinal stimulation in patients with retinitis pigmentosa. Investigative ophthalmology \& visual science. 2011;52:4726-33.

[10] Brindley GS, Lewin WS. The sensations produced by electrical stimulation of the visual cortex. The Journal of physiology. 1968;196:479-93.

[11] Dobelle WH. Artificial vision for the blind by connecting a television camera to the visual cortex. Asaio J. 2000;46:3-9.

[12] Cha K, Horch KW, Normann RA. Mobility performance with a pixelized vision system. Vision research. 1992;32:1367-72.

[13] Cha K, Horch KW, Normann RA, Boman DK. Reading speed with a pixelized vision system. J Opt Soc Am A. 1992;9:673-7.

[14] Sommerhalder J, Rappaz B, de Haller R, Fornos AP, Safran AB, Pelizzone M. Simulation of artificial vision: II. Eccentric reading of full-page text and the learning of this task. Vision research. 2004;44:1693-706.

[15] Stett A, Barth W, Weiss S, Haemmerle H, Zrenner E. Electrical multisite stimulation of the isolated chicken retina. Vision research. 2000;40:1785-95.

[16] Joucla S, Yvert B. Improved focalization of electrical microstimulation using microelectrode arrays: a modeling study. PloS one. 2009;4:e4828.

[17] Matteucci PB, Chen SC, Tsai D, Dodds CW, Dokos S, Morley JW, et al. Current steering in retinal stimulation via a quasimonopolar stimulation paradigm. Investigative ophthalmology \& visual science. 2013;54:4307-20.

[18] Khalili Moghadam G, Wilke R, Suaning GJ, Lovell NH, Dokos S. Quasi-monopolar stimulation: a novel electrode design configuration for performance optimization of a retinal neuroprosthesis. PloS one. 2013;8:e73130. 
[19] Butterwick A, Huie P, Jones BW, Marc RE, Marmor M, Palanker D. Effect of shape and coating of a subretinal prosthesis on its integration with the retina. Experimental eye research. 2009;88:22-9.

[20] Djilas M, Oles C, Lorach H, Bendali A, Degardin J, Dubus E, et al. Three-dimensional electrode arrays for retinal prostheses: modeling, geometry optimization and experimental validation. Journal of neural engineering. 2011;8:046020.

[21] Palanker D, Huie P, Vankov A, Aramant R, Seiler M, Fishman H, et al. Migration of retinal cells through a perforated membrane: implications for a high-resolution prosthesis. Investigative ophthalmology \& visual science. 2004;45:3266-70.

[22] Palanker D, Vankov A, Huie P, Baccus S. Design of a high-resolution optoelectronic retinal prosthesis. Journal of neural engineering. 2005;2:S105-20.

[23] Cogan SF. Neural stimulation and recording electrodes. Annual review of biomedical engineering. 2008;10:275-309.

[24] Garrett DJ, Ganesan K, Stacey A, Fox K, Meffin H, Prawer S. Ultra-nanocrystalline diamond electrodes: optimization towards neural stimulation applications. Journal of neural engineering. 2012;9:016002.

[25] Kiran R, Rousseau L, Lissorgues G, Scorsone E, Bongrain A, Yvert B, et al. Multichannel boron doped nanocrystalline diamond ultramicroelectrode arrays: design, fabrication and characterization. Sensors (Basel). 2012;12:7669-81.

[26] Girard HA, Perruchas S, Gesset C, Chaigneau M, Vieille L, Arnault JC, et al. Electrostatic grafting of diamond nanoparticles: a versatile route to nanocrystalline diamond thin films. ACS Appl Mater Interfaces. 2009;1:2738-46.

[27] Hébert C, Mazellier JP, Scorsone E, Mermoux M, Bergonzo P. Boosting the electrochemical properties of diamond electrodes using carbon nanotube scaffolds. Carbon. 2014;71:27-33.

[28] Hadjinicolaou AE, Leung RT, Garrett DJ, Ganesan K, Fox K, Nayagam DA, et al. Electrical stimulation of retinal ganglion cells with diamond and the development of an all diamond retinal prosthesis. Biomaterials. 2012;33:5812-20.

[29] Thalhammer A, Edgington RJ, Cingolani LA, Schoepfer R, Jackman RB. The use of nanodiamond monolayer coatings to promote the formation of functional neuronal networks. Biomaterials 2010;31:2097-104.

[30] Chen YC, Lee DC, Hsiao CY, Chung YF, Chen HC, Thomas JP, et al. The effect of ultra-nanocrystalline diamond films on the proliferation and differentiation of neural stem cells. Biomaterials. 2009;30:3428-35.

[31] Chen YC, Lee DC, Tsai TY, Hsiao CY, Liu JW, Kao CY, et al. Induction and regulation of differentiation in neural stem cells on ultra-nanocrystalline diamond films. Biomaterials. 2010;31:5575-87.

[32] Specht CG, Williams OA, Jackman RB, Schoepfer R. Ordered growth of neurons on diamond. Biomaterials. 2004;25:4073-8.

[33] Bendali A, Agnes C, Meffert S, Forster V, Bongrain A, Arnault JC, et al. Distinctive glial and neuronal interfacing on nanocrystalline diamond. PloS one. 2014;9:e92562.

[34] Rizzo JF, 3rd, Wyatt J, Loewenstein J, Kelly S, Shire D. Methods and perceptual thresholds for short-term electrical stimulation of human retina with microelectrode arrays. Investigative ophthalmology \& visual science. 2003;44:5355-61. [35] Bongrain A, Scorsone E, Rousseau L, Lissorgues G, Gesset C, Saada S, et al. Selective nucleation in silicon moulds for diamond MEMS fabrication. . J Micromech Microeng 2009;19:074015.

[36] Salzmann J, Linderholm OP, Guyomard JL, Paques M, Simonutti M, Lecchi M, et al. Subretinal electrode implantation in the $\mathrm{P} 23 \mathrm{H}$ rat for chronic stimulations. The British journal of ophthalmology. 2006;90:1183-7. 
1 [37] Klinge PM, Vafa MA, Brinker T, Brandis A, Walter GF, Stieglitz T, et al. 2 Immunohistochemical characterization of axonal sprouting and reactive tissue changes after 3 long-term implantation of a polyimide sieve electrode to the transected adult rat sciatic nerve. 4 Biomaterials. 2001;22:2333-43.

5 [38] Machida S, Kondo M, Jamison JA, Khan NW, Kononen LT, Sugawara T, et al. P23H 6 rhodopsin transgenic rat: correlation of retinal function with histopathology. Investigative 7 ophthalmology \& visual science. 2000;41:3200-9.

8 [39] Linderholm P, Guyomard JL, Djilas M, Salzmann J, Simonutti M, Sahel JA, et al. Long9 term in vivo impedance changes of subretinal microelectrodes implanted in dystrophic $\mathrm{P} 23 \mathrm{H}$ 10 rats. Int J Artif Organs. 2013:DOI:10.5301/ijao.5000213.

11 [40] da Cruz L, Coley BF, Dorn J, Merlini F, Filley E, Christopher P, et al. The Argus II 12 epiretinal prosthesis system allows letter and word reading and long-term function in patients 13 with profound vision loss. The British journal of ophthalmology. 2013;97:632-6.

14 [41] Ganesan K, Garrett DJ, Ahnood A, Shivdasani MN, Tong W, Turnley AM, et al. An all15 diamond, hermetic electrical feedthrough array for a retinal prosthesis. Biomaterials. 16 2014;35:908-15. 
2 Figure legends

3 Figure 1: Grey-scale image of Abraham Lincoln with 256 grey-scale levels before (A) and after down 4 sampling to $25 \times 25$ pixels and reducing the colour palette to 3 grey-scale levels (B). The brightness ranges covered by the 3 intensity levels are shown on the colour bar on the right. Current density profiles along the red line, with the image encoded on a $25 \times 25$ electrode array, are shown in the next figure. The current densities above the cathode are represented in these four configurations: i) planar electrode array with a returning ground grid $(\mathbf{C})$, ii) 3D electrode array with a returning ground grid (D), iii) planar electrode array with a distant ground (E), iv) 3D electrode array with a distant ground $(\mathbf{F})$.

Figure 2: Amplitude of current densities for different grey level stimulations. Current density plots along the red line from the previous figure, $20 \mu \mathrm{m}$ and $40 \mu \mathrm{m}$ above the $25 \times 25$ electrode array, on which the Lincoln image has been encoded with 3 intensity levels: no current injected for white pixels, $1000 \mathrm{~A} / \mathrm{cm}^{2}$ for grey, and $2000 \mathrm{~A} / \mathrm{cm}^{2}$ for black. A: $20 \mu \mathrm{m}$ above the planar electrode array with a distant counter electrode; B: $20 \mu \mathrm{m}$ above the three-dimensional array with a distant counter electrode; C: $20 \mu \mathrm{m}$ above the planar array with the counter electrode surrounding the wells; $\mathbf{D}: 20 \mu \mathrm{m}$ above the three-dimensional array with the counter electrode surrounding the wells; E: $40 \mu \mathrm{m}$ above the planar electrode array with a distant counter electrode; F: $40 \mu \mathrm{m}$ above the three-dimensional array with a distant counter electrode; G: $40 \mu \mathrm{m}$ above the planar array with the counter electrode surrounding the wells; $\mathbf{H}: 40 \mu \mathrm{m}$ above the three-dimensional array with the counter electrode surrounding the wells. I,J) Quantification of current densities for all the pixels of the Lincoln image with the different configurations at $20 \mu \mathrm{m}(\mathrm{I})$ and $40 \mu \mathrm{m}(\mathrm{J})$ above the electrodes (Mean $\pm \mathrm{SD}$ ).

Figure 3: Production of flexible diamond implants. A: Diagram of the microfabrication steps with nano-diamond seeding and selective diamond growth followed by polyimide addition; B: Picture of the mask (Yellow: KOH 3D structures, grey shape of implant); C: SEM picture of the silicon mould; D: Final dummy implant for in vivo evaluation. 
2 Figure 4: Eye fundus of $\mathrm{P} 23 \mathrm{H}$ rats with implanted polyimide (A), diamond (B) and metallic (C)

3 devices. The scale bar is $500 \mu \mathrm{m}$.

4

5 Figure 5: Confocal imaging of stained retinae in contact with implants, 2 views. A-C: top views of whole-mount retinae along view "a" (top of the cavities); D-F: top views along view "b" (bottom of the cavities); G-H: orthogonal views indicating the points from which views "a" and "b" were taken.

A, D, G: DAPI staining of all cell nuclei; B, E, H: ON bipolar cells stained with anti-Goalpha antibody; C, F: coloured merged images of both DAPI and Goalpha staining (DAPI in blue and Goalpha in green).

Figure 6: Quantification of bipolar cells within the 3D electrodes for each material. A-C: Image processing for cell counting with preprocessing (A), Imaris nucleus counting (B) and manual bipolar cell counting (C); D-G: plots of cell numbers for each cavity; D: number of cell nuclei per volume; $\mathbf{E}$ : mean number of cell nuclei per volume; F: proportion of bipolar cells, expressed as a percentage of the total number of cell nuclei; G: mean value of the ratio of bipolar cells to total nuclei.

Figure 7: Examination of the materials used by scanning electron microscopy, following in vivo implantation: after fabrication during which the polyimide layer is lifted off the structure shown in Fig3C, the $20 \mu$ m-thick foils were surgically implanted in rats for 8 weeks, then explanted and prepared for SEM observations. The pictures display the naked polyimide surface $(\mathbf{A}, \mathbf{D})$, and the same covered by a thin diamond layer $(\mathbf{B}, \mathbf{E})$, or metal $(\mathbf{C}, \mathbf{F})$. Although the numerous processes that significantly altered the edges of the thin polyimide foils, the images display that the surface qualities remained unchanged during the implantation period. For all these implants, residual cells or tissues are visible within the cavities on the enlarged views (D-F). 


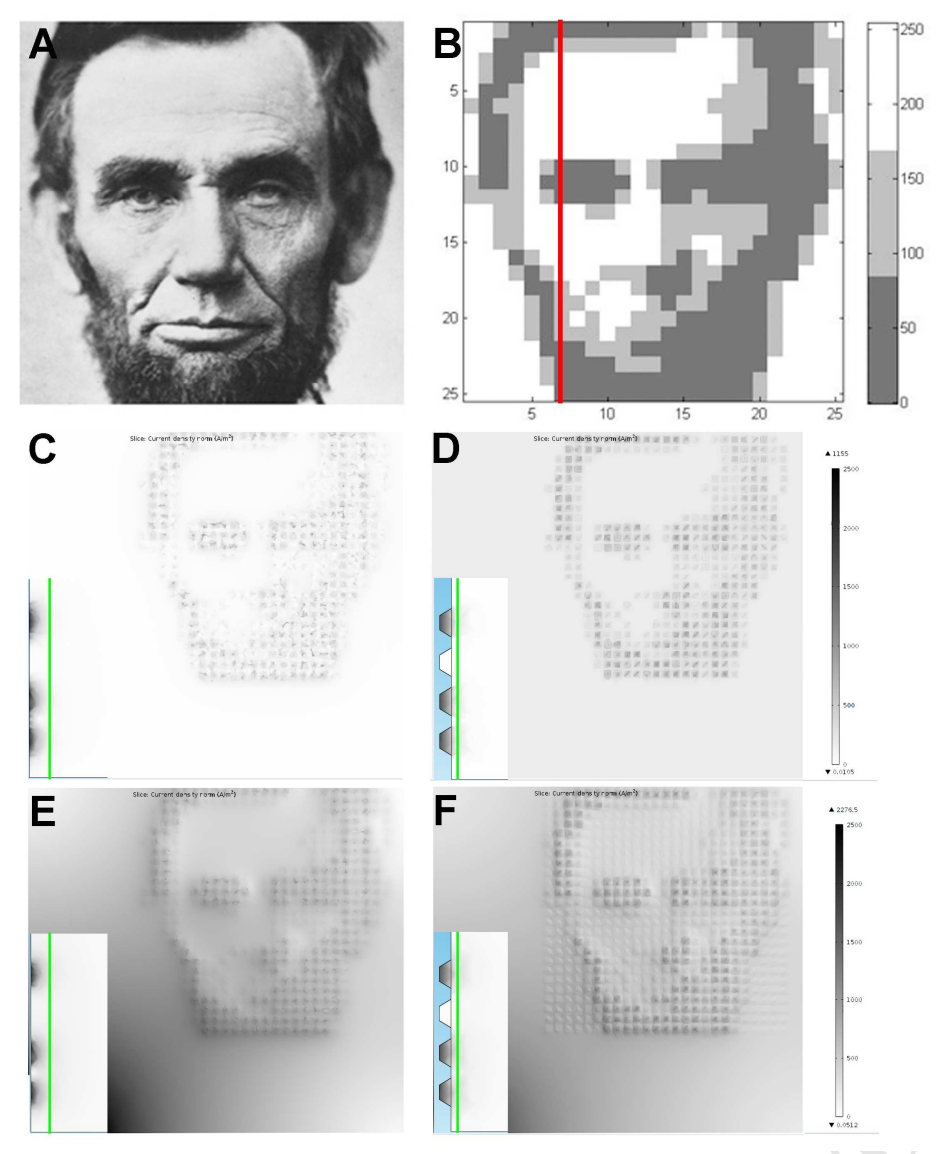




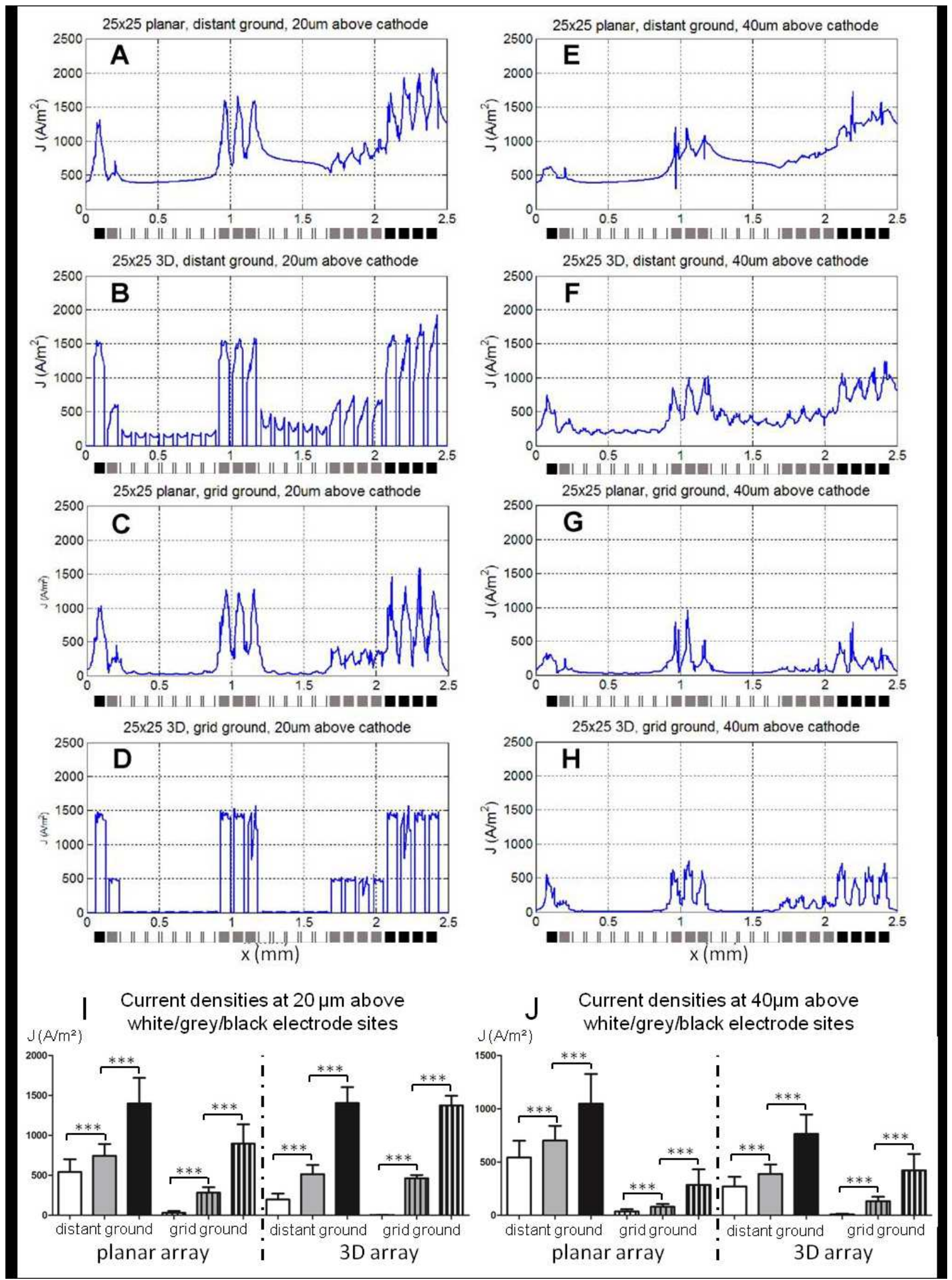




\section{A Fabrication process B}

1- KOH Etching \& Oxidation

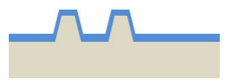

2- Diamond Growth

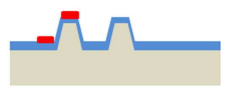

3- Metal deposition

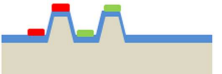

4- Polyimide deposition

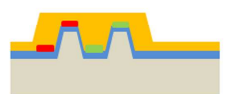

5- Etching

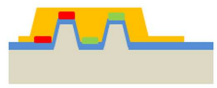

6- Implant Peel-off
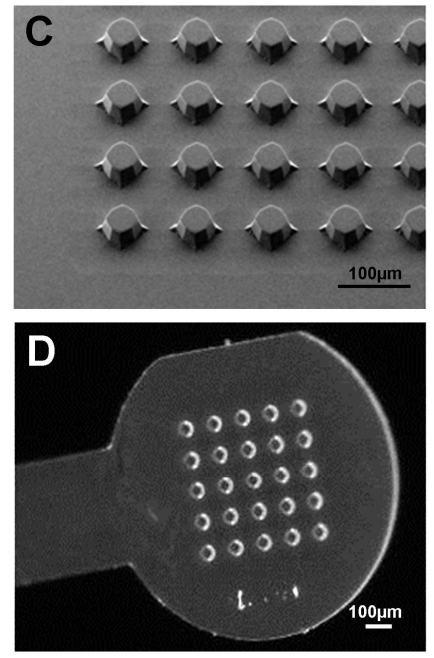


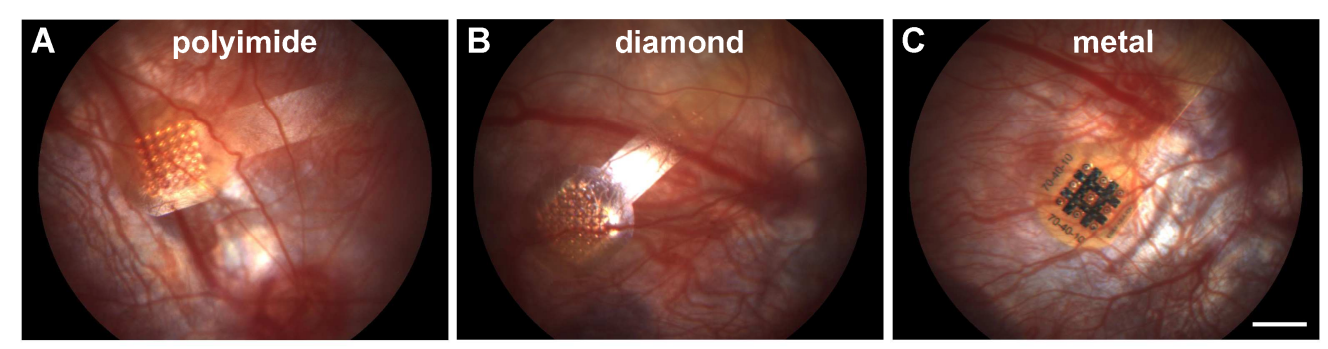




\section{ACCEPTED MANUSCRIPT}

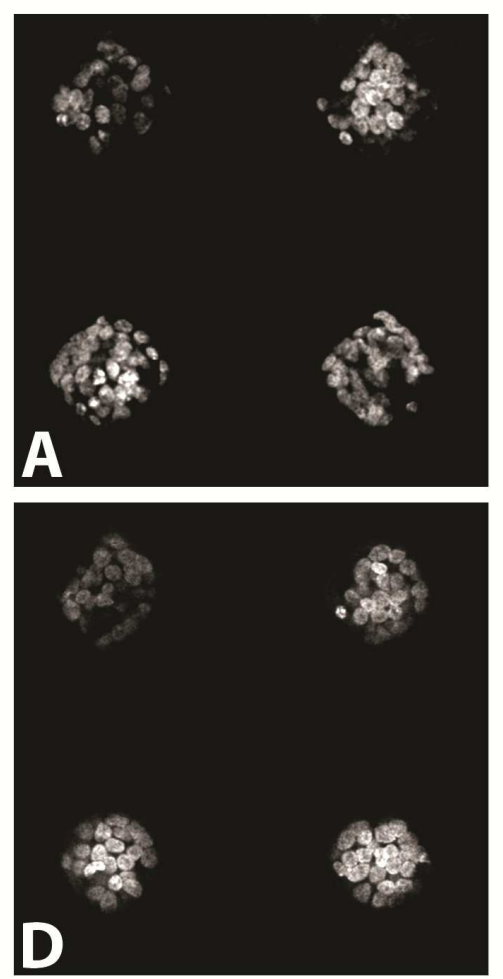

Nuclei
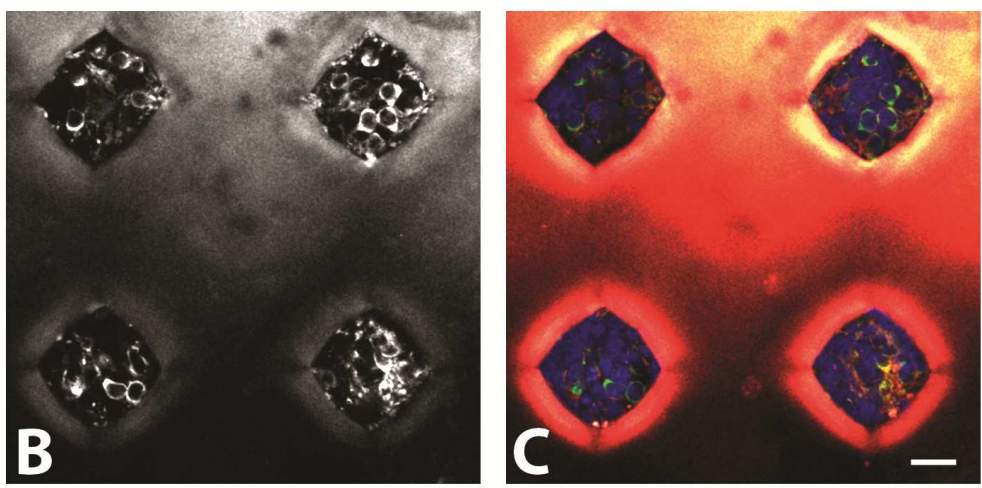

$\sum_{0}^{\frac{1}{D}}$

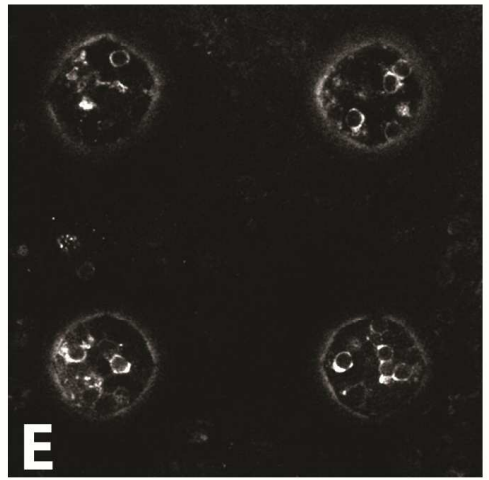

Bipolar cells

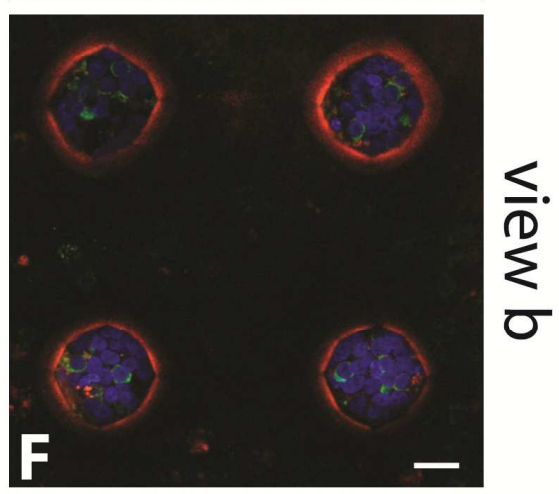

Merge

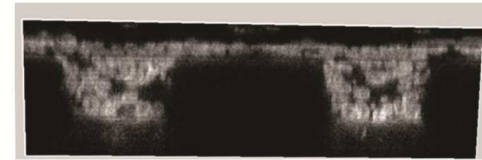

Orthogonal view - Nuclei

$\mathbf{G}$

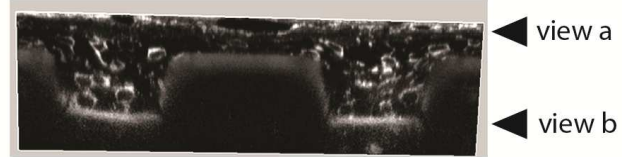

Orthogonal view - Bipolar cells H 


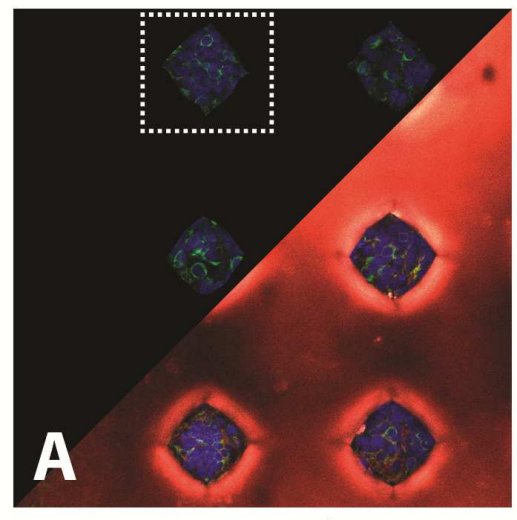

preprocessing

D

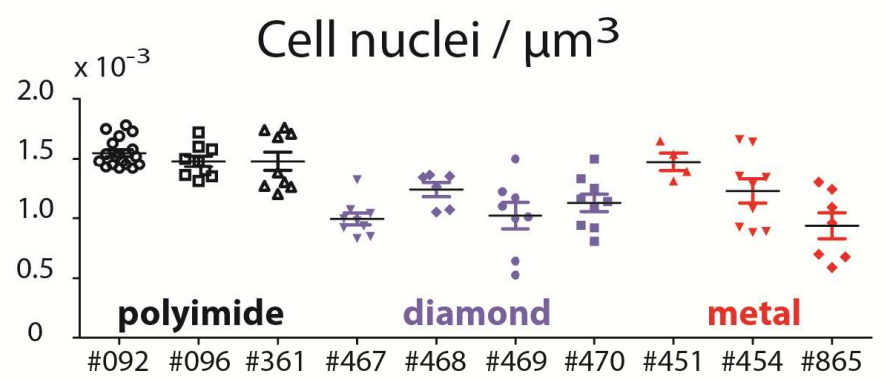

F

Bipolar cells vs all cell nuclei (\%)

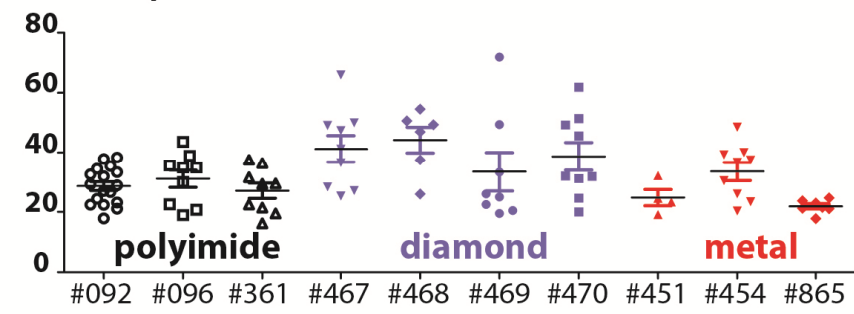

\section{H}

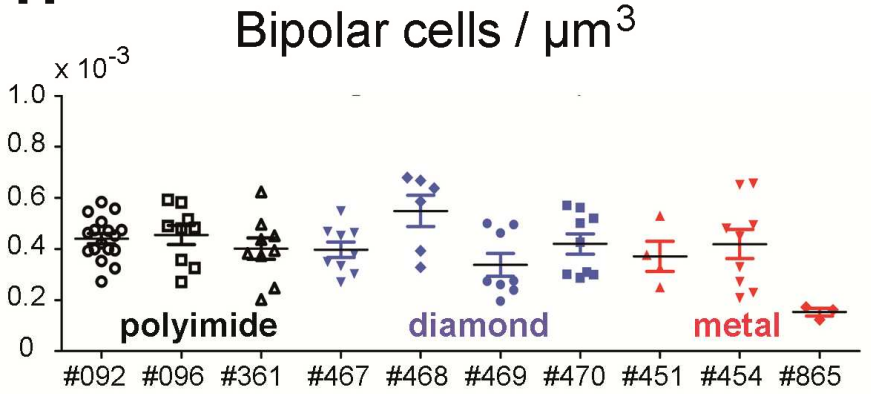

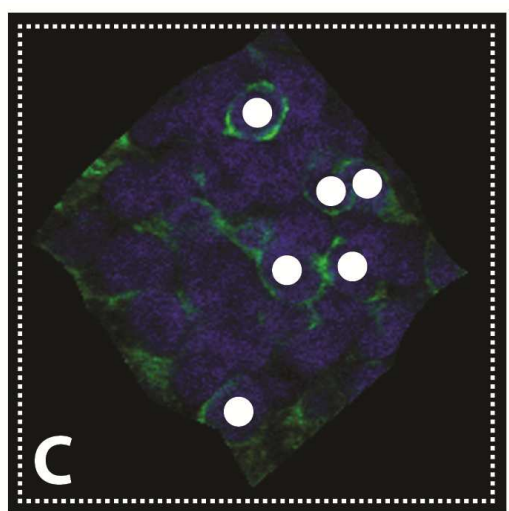

manual bipolar cell counting

E Mean number of cell nuclei / $\mu^{3}{ }^{3}$

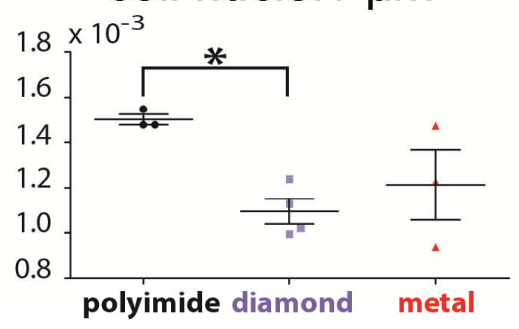

G

Mean of bip/dapi ratio

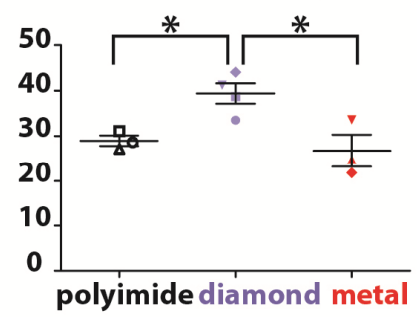

I Mean number of bipolar

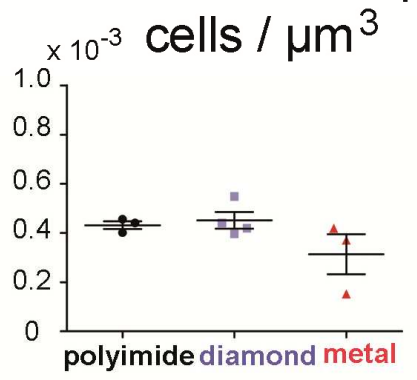




\section{ACCEPTED MANUSCRIPT}
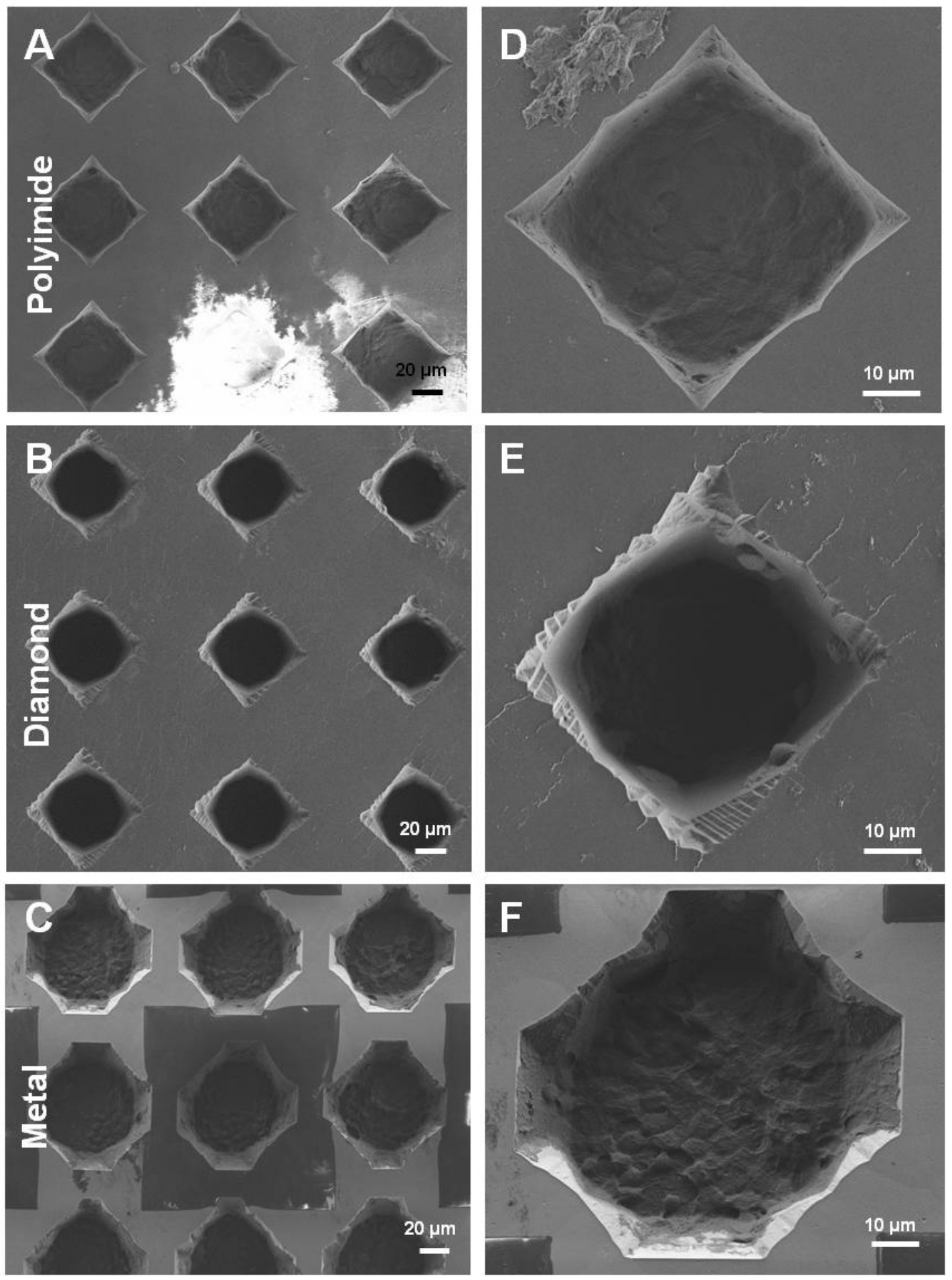